\title{
Study on potential environmental adsorption of egg shells to removal of lead and cadmium from Oryza sativa rice
}

\author{
Sahar Gorgani' ${ }^{1}$ Parisa Ziarati ${ }^{2}$ \\ ${ }^{I}$ MSc in Food Sciences, Nutrition and Food Sciences Research Center, Tehran Medical Sciences, Islamic Azad \\ University, Tehran, Iran \\ ${ }^{2}$ Faculty member and Head of Nutrition and Food Sciences Research Center, Tehran Medical Sciences, Islamic Azad \\ University, Tehran, Iran
}

\begin{abstract}
Background: Removal of heavy metal ions from contaminated systems by agricultural and fruit and vegetable processing waste materials is an innovative and auspicious technology .The current study was designed for utilization of bio-adsorption white hard eggshell, as less expensive and much frequently available food waste materials, due to prospective metal bio-sorption capacity to toxic heavy metal ions, including cadmium $(\mathrm{Cd})$ and lead $(\mathrm{Pb})$ from Oryza sativa in Iran.

Materials and methods: The effect of soaking rinsed rice samples by $\mathrm{NaCl} 2 \%$ and modified white eggshell adsorbent by different concentration as adsorbent, $\mathrm{pH}$, contact time and association of cooking methods on cadmium and lead contents were studied. Heavy metal contents in raw, rinsed, soaked by adsorbent and cooked and drained rice samples were determined by flame atomic absorption spectrophotometer in 925 samples in 4 different state of raw, soaking, cooked and drained.

Results: Cooking rice by soaking rinsed rice samples by $\mathrm{NaCl} 2 \%$ and white eggshell for 1 hour had the greatest effect with regards to removal of $\mathrm{Pb}$ and $\mathrm{Cd}$ levels in cooked rice. It significantly reduced the cadmium content by $90.35 \%$ and lead content by $91.21 \%$ from the cooked rice, when soaked by white eggshell for one hour contact time.

Conclusion: The results of the current study suggest that eggshell waste adsorbent can be used beneficially in treating rice containing heavy metal ions.

Keywords: Heavy metal removal, Adsorption, White eggshell, Oryza sativa rice.

Cited as: Gorgani S, Ziarati P. Study on Potential Environmental Adsorption of Egg shells to Removal of Lead and Cadmium from Oriza Sativa Rice. Medical Science Journal of Islamic Azad University, Tehran Medical Branch 2020; 30(2): 155-166.

Correspondence to: Parisa Ziarati

Tel: +9821 22140051

E-mail: ziarati.p@iaups.ac.ir

ORCID ID: 0000-0002-9802-9949

Received: 31 Aug 2019; Accepted: 1 Jun 2020
\end{abstract}


مجله علوم يزشكى دانشعاه آزاد اسلامى

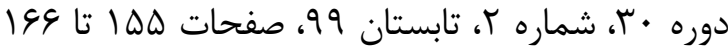

\section{بررسى و تهيه جاذب سطحى زيست محيطى با استفاده از يوسته تخم مرغ در حذف فلزات سرب و كادميوم از برنج هاشمى سحر تركانى'، يريسا زيارتى}

' ' كارشناسى ارشد علوم صنايع غذايى، مركز تحقيقات علوم تغذيه و صنايع غذايى، علوم يزشكى تهران، دانشكاه آزاد اسلامى، تهران، ايران

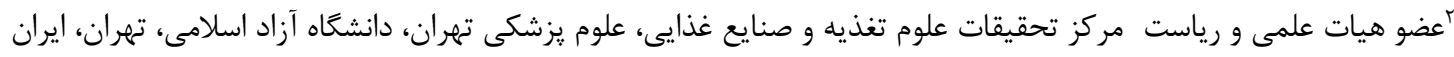

سابقه و هدف: ضايعات محصولات كشاورزى و مواد غذايى با فرآورى مناسب مىتواند در توليد انواع محصولات /رزشمند مورد /ستفاده

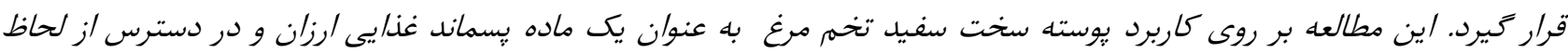

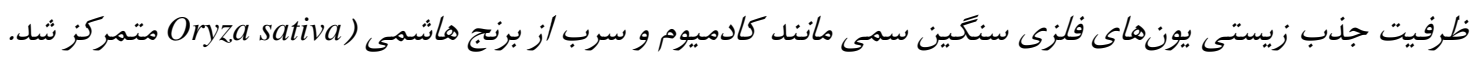

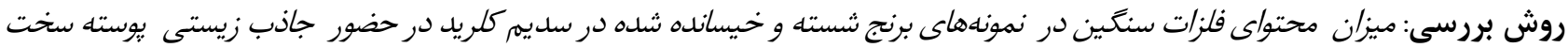

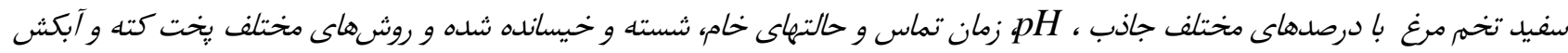

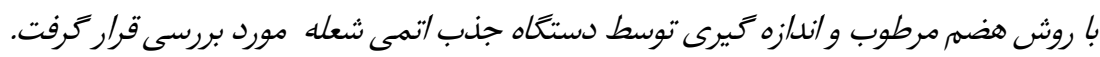

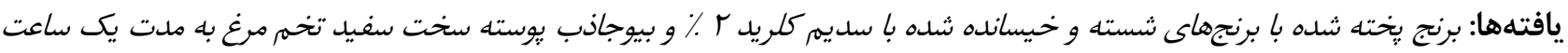

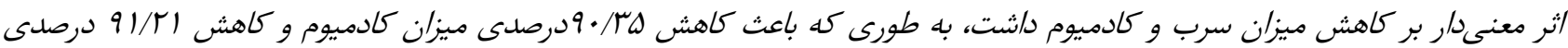

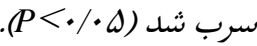
نتيجه كيرى: نتايج مطالعه اخير نشان داد كه بيو جاذب يوسته سخت سفيد تخمم مغ در هنكام خيساندن برنج تاثير معنى ارىى در حذف

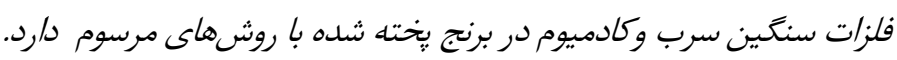

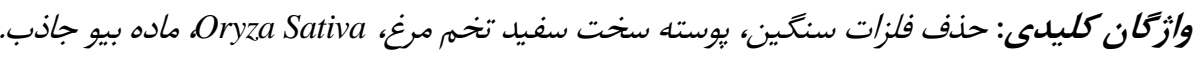

زإين، ايتاليا، مصر، اسيانيا ، جين، برزيل، مكزيك و اسـتر اليا از

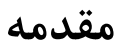
جمله كشورهاى توليد كننده برنج به شـمار مسىرونـد. ميـزان

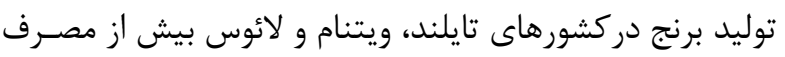

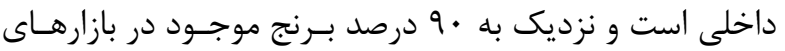

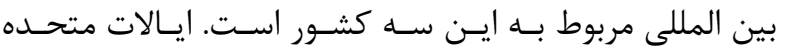

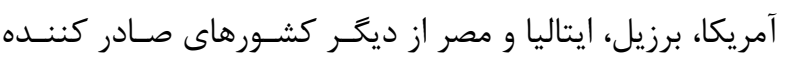

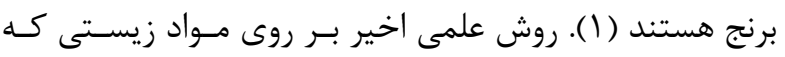

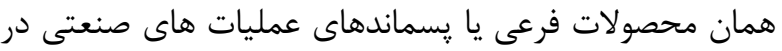
مقياس بزرى و مواد كشاورزى پِماند و يا حتسى يسـماندهاى

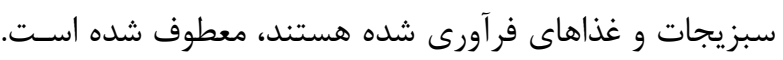

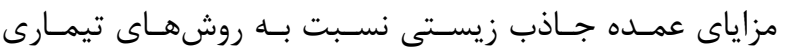

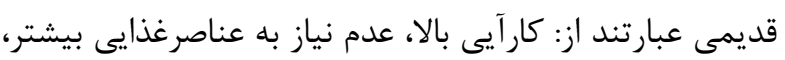

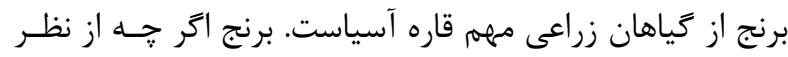

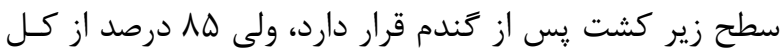

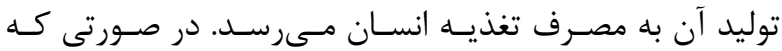

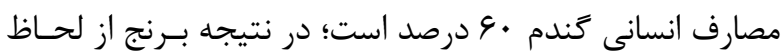

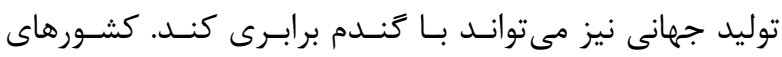

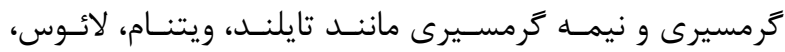
اندونزى، فيلييين، پاكستان، هندوستان، ايالات متحده آمريكـا،

أدرس نويسنده مسئول: تهران، داتشخاه آزاد اسلامى، مركز تحقيقات علوم تغذيه و صـنايع غـذايى، يريسـا

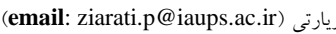
ORCID ID: 0000-0002-9802-9949 تاريخ دريافت مقاله: :

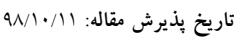


اندازه جاذب زيستى، pH، قدرت يونى و دمـاى تاثيركـذار بـر

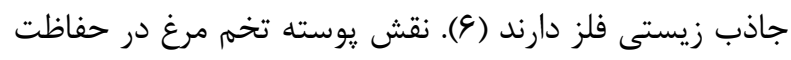

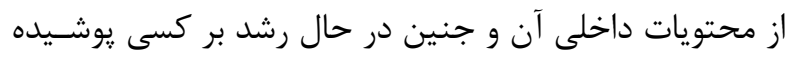

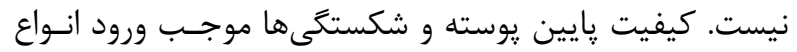

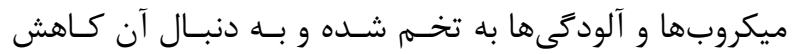

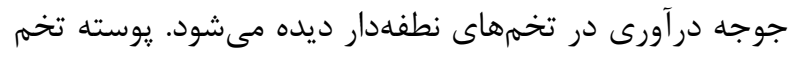

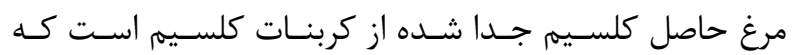
معمولاً اين كلسيم از طريق خوراك و و منابع متابوليـك حساوى

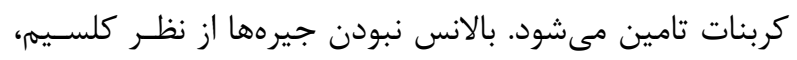

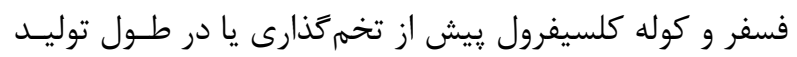

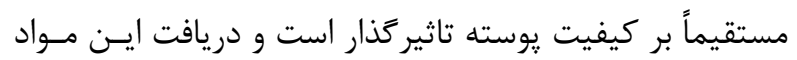
مغذى به خصوص در شرايط استرس كَرمـايى بسيار مهـهم بــهـ

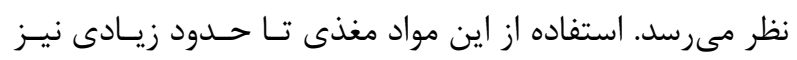

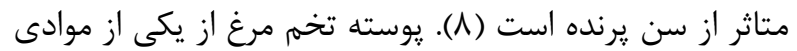

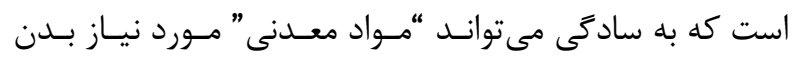

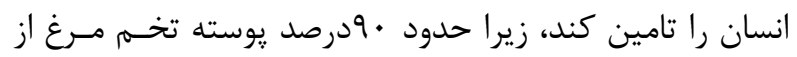

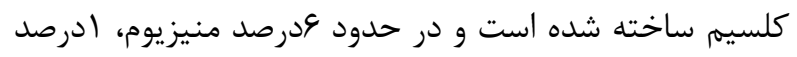

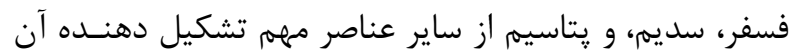

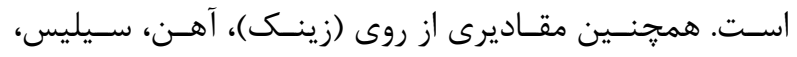

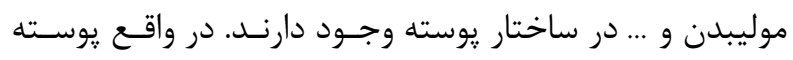
تخمم مرغ منبع بسيار خوبى براى كلسيم، منيزيـوم، رِتاسـيمه و

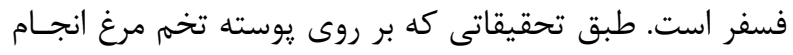

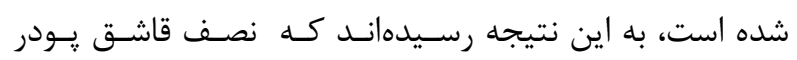

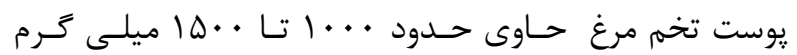

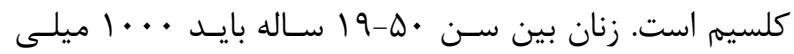

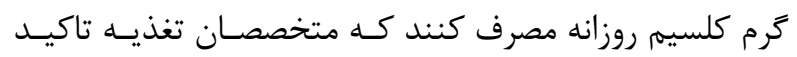

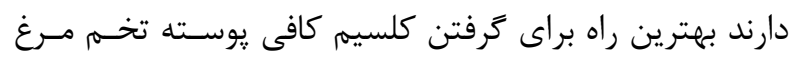

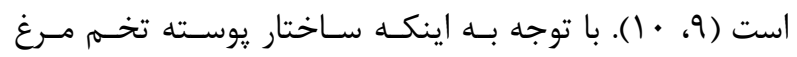

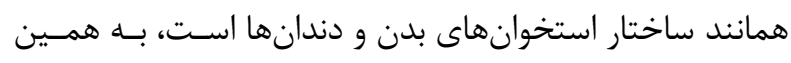

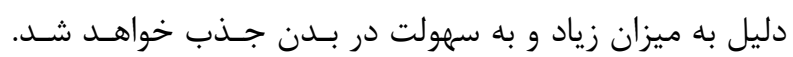
مصرف مقدار كمى از يوسته تخم مرغ به صورت روزانه انسـان

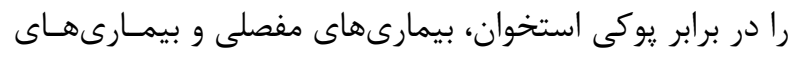

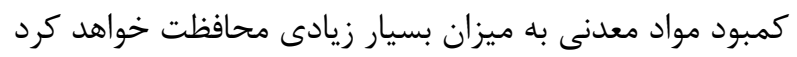

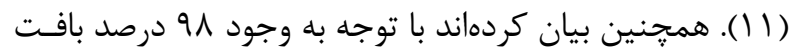

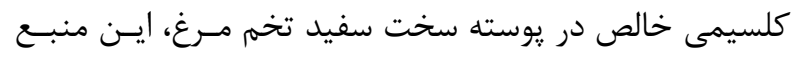

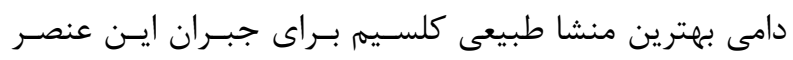

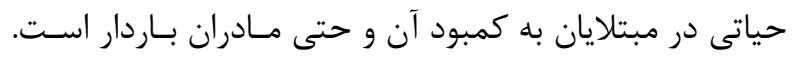

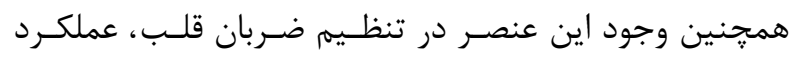

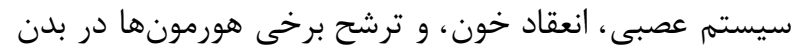

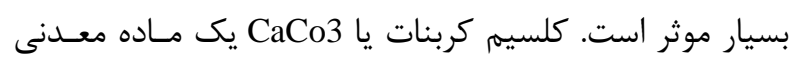

قيمت يايين، به حداقل رساندن لجنهاى شيميايى يا زيسـتى

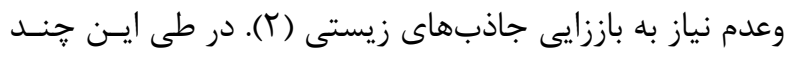

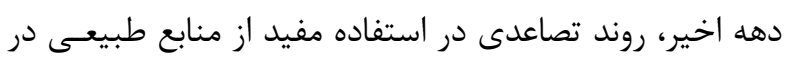
سراسر جهان مشاهده شده است. دسترسى مستقيم به بقايساى

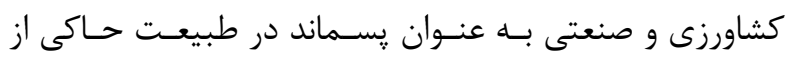

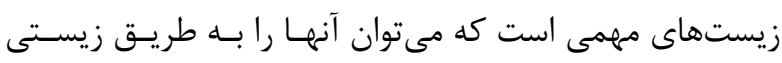

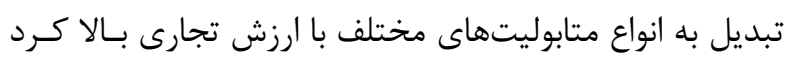

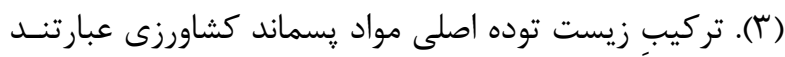

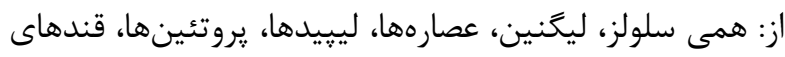

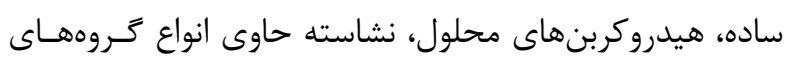

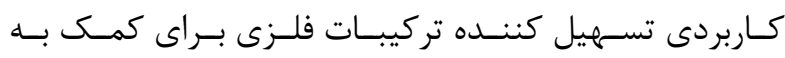

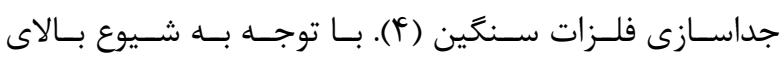

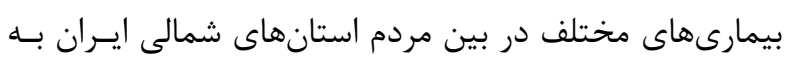

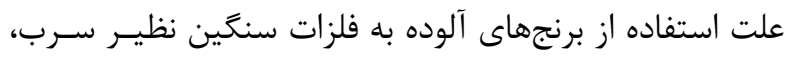

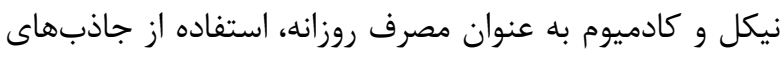

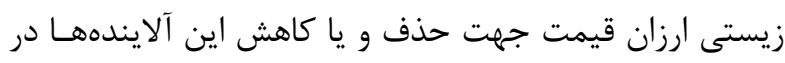

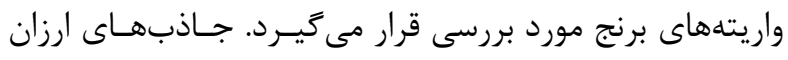

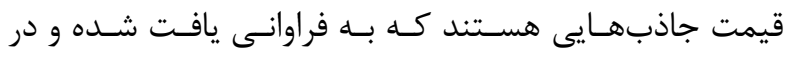

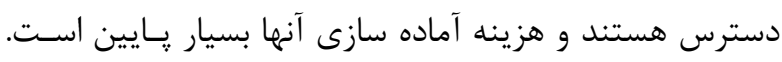

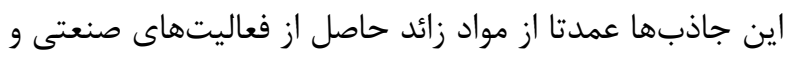

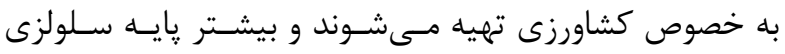

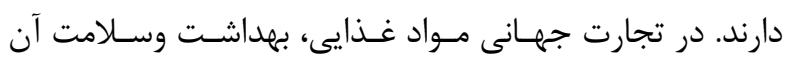

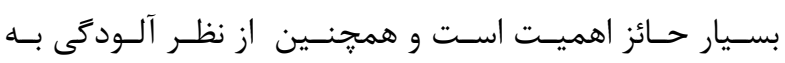

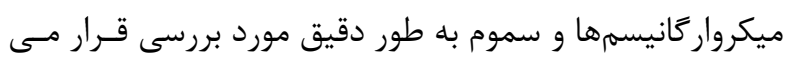

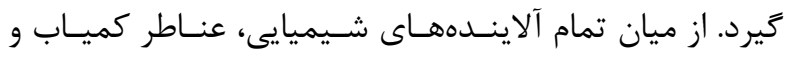

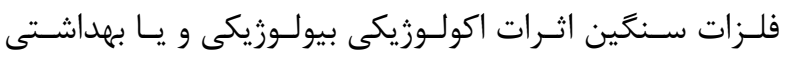

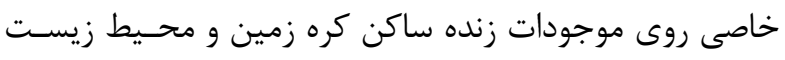

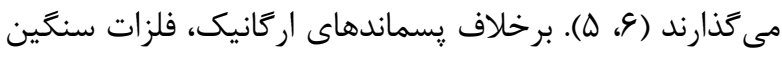

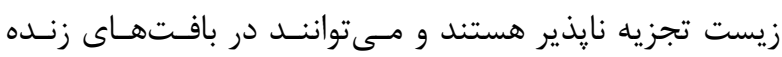

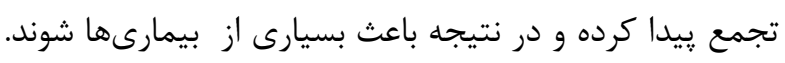

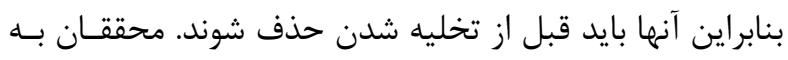

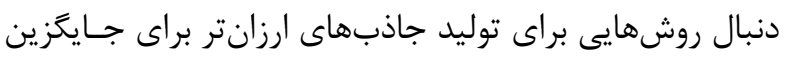

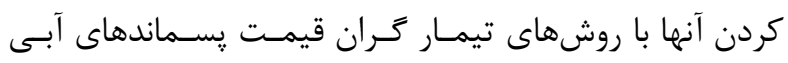

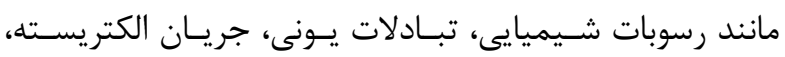
جداسازى غشاء، خاصيت نفوذ معكوس، الكترودياليز، استخراج

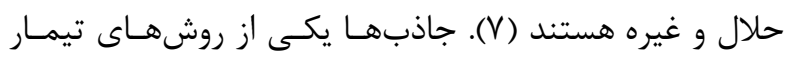

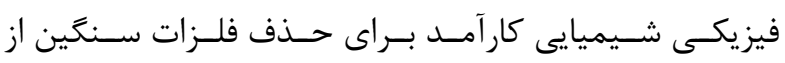

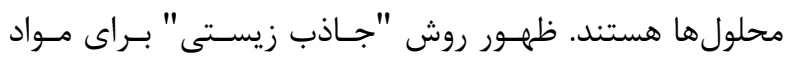

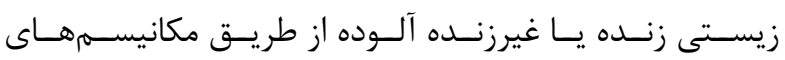

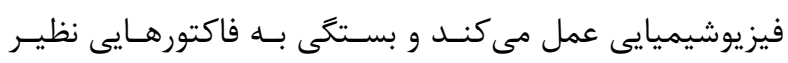


كَرفت. تمامى انواع بوسته سخت سـفيد تخـهم مـرغ بـراى حـذف كـ زيستى كادميوم و سرب از نمونه برنج هاى خيسـانده شـده تحـت شرايط مختلف مانند غلظت هاى يوسته سخت سفيد تخم مـرغ و و و زمان تماس مورد آزمايش قرار گرفتند.

\section{روش نمونه گيرى برنج}

أ نمونـهـ بــرنج ايرانسى از نـوع هاشـمى (Oryza sativa) از اسـتان

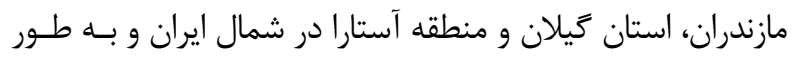
تصادفى از · ا برند مشهور و شناخته شده از فروشعاه هاى بـزرى

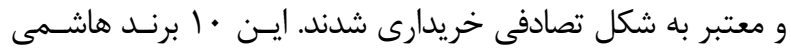

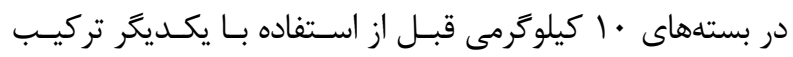

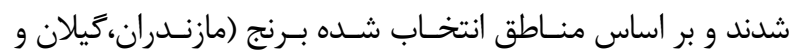

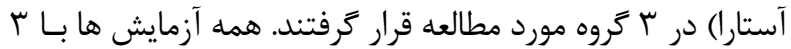

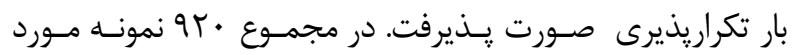
بر بـى قرار كرفتند. آزمايش برزيت غلظت فلزات سنَين سرب و كادميوم در برنجهـاى خـام، شســه

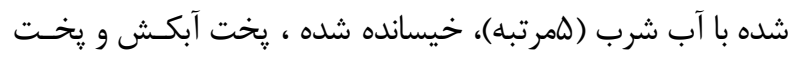

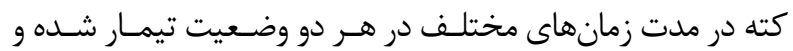
تيمار نشده از طريق روش هضم مرطوب و با استفاده از • ا آــرم از هر نمونه برنج هاشمى و همجنين رعايت اصول آناليز از يروتوكـل

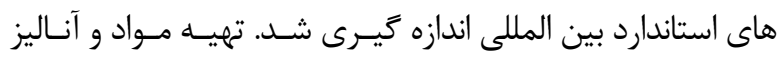
محتواى فلزات سنگَين با دسـتخاه اسـيكتروفتومتر جـذبى اتمسى براساس كتاب سالانه استانداردهاى ASTM (انجمن مواد و آزمــون آمريكا) و AOAC (انجمن رسمى شيمى دانسان كشـاورزى) انجـام

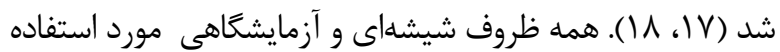

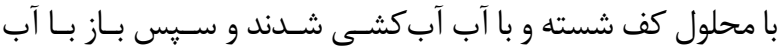

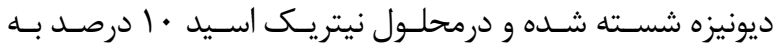
مدت TF ساعت غوطه ور شدند. سيس به طور كامل بـا آب مقطـــ شسته و خشك شده تا از فقدان هرگَونه آلودگى اطمينان حاصـل شود. شاهدها و نمونهها فر آورى و به سرعت آناليز شدند. همه مواد

شيميايى مورد درجه بندى آمارى (AR) استفاده شدند (19 (1).

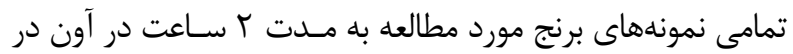

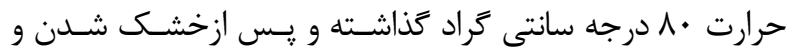

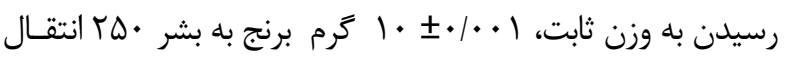

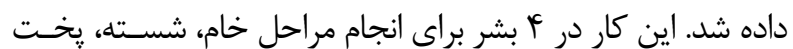

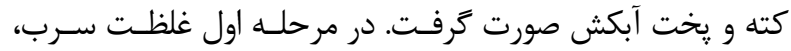
كادميم و نيكل در برنج خام اندازه گيرى شد، به طورى كه به بعـد از

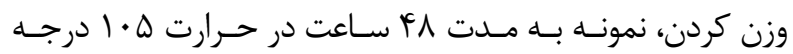
سانتى گراد قرار گرفت. در هردو وضعيت تيمار شده و تيمار نشـده با يوسته تخم مرغ مراحل زير انجام شد. ابتدا يس از خشك كردن
استثنايى است كه در يوسته تخم مرغ نيز موجـود اسـت و در كاهش فلزات سنگين بسيار موثر اسـت (T (، سا). كلسـيم در بدن در انتقال ييامهاى عصبى با واسطه يون كلسـيه، عملكـرد

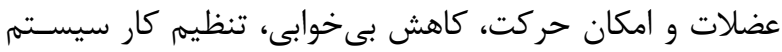
اعصاب بدن به خصوص در انتقال تحريكـات، متابوليسـم آهـن بدن، تنظيم ضربان قلب و استحكام استخوانها نقـش اساسـى

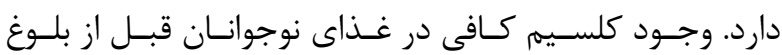

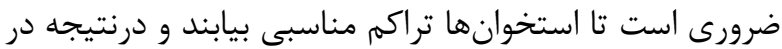

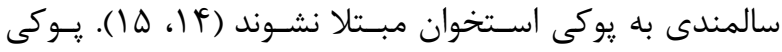

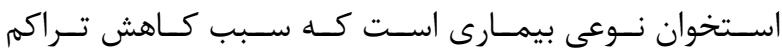

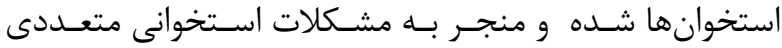
مىشود كه در آن كاهش توده استخوانى مىتواند به شكستخى

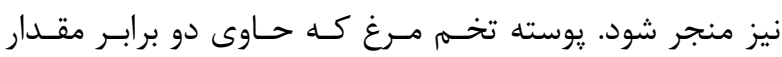

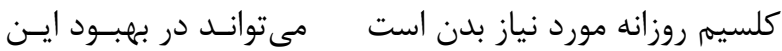
بيمارى بسيار موثر باشد؛ در نتيجه از يوسته تخمم مرغ به دليل

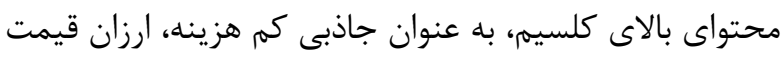

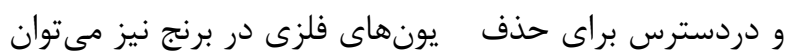
به كار برد (ع) (1). بنابراين، اين مطالعـهـ بـر روى كـاربرد يوســـه سخت سفيد تخم مرغ به عنوان يك ماده يسماند غذايى ارزان

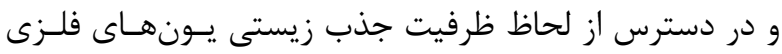

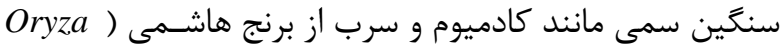
(sativa

\section{مواد و روشها - (- مواد جاذب زيستى}

در اين مطالعه يوسته سخت سفيد تخمم مـرغ (White Eggshell)

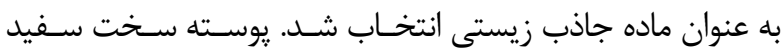
تخم مرغ را با آب كاملا شسته شده تا آلـودَى هـاى احتمـالى در

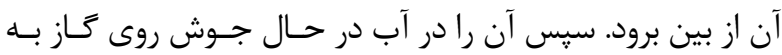

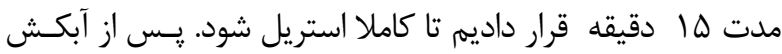
كردن، آن را به ظرفى كه از قبل استريل شده بود منتقـل كـرديم. سيس آن را به طور طبيعى در برابـر تـابش مسـتقيهم آفتـاب قـرار

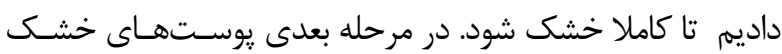

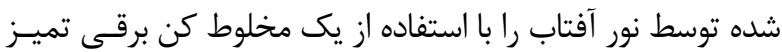

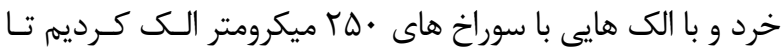

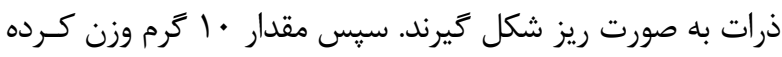
و در بوته جينى ريخته و به مدت r باعت در آون در حـرارت درجه سانتى گَراد گذاشـته تـا بـهـ وزن ثابـت برسـد. اسـتفاده از بيوجاذبها به صورت بستههـايى از جــس كاغـذ صـافى صـورت 
رسانده شد ( (Y). سيس نمونهها يـس از سـانتريفوز شـدن و جــدا شدن محلول شفاف به دستخاه طيف سنج جـذب اتمسى شـعله بـاــا

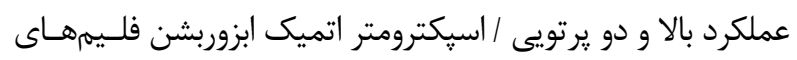

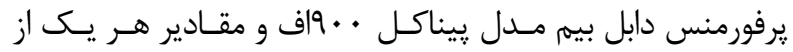

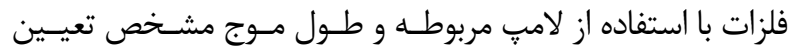
شده در يروتكل هاى بين المللى ارزيابى شد.

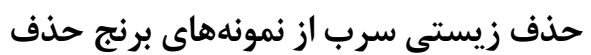

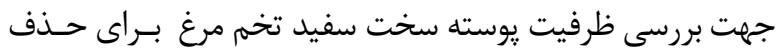

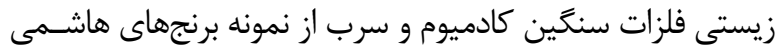

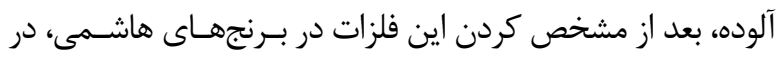

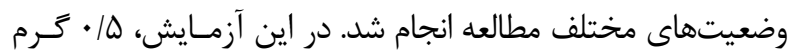
يودر خشك شده يوسته سخت تخم مرغ به سه فرم يودر قطعـات خشك شده، به فرم كربن فعال ايجاد شده از يوسته سـخت سـفيد

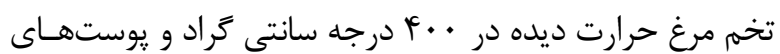
يودر شده تيمار شده با فسفريك اسيد ا درصد، درون تانكهاى

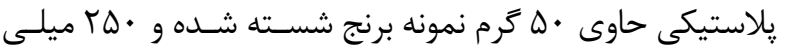

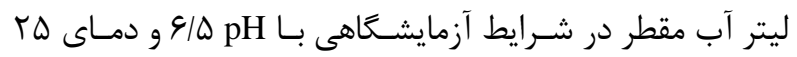
درجه سانتى گراد به مدت ا ساعت به حال خود رها شد. نيمسى سلى

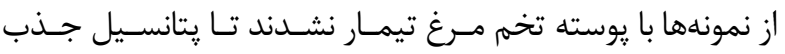
زيستى آنها مشخص شود. غلظت فلز زيست جذب شده (mg/l) و

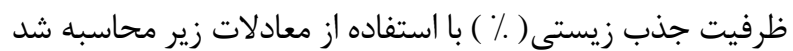

Ci - Cf =)(mg/l) غلظت فلز زيست جذب شده (1)

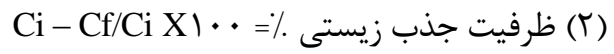
در اين معادله Ci= غلظت اوليه فلز و Cf= غلظت نهايى فلز

\section{ارزيابى ريسك خطر} به منظور ارزيابى يتانسيل خطر مصرف بـرنج هـاى حساوى فلـزات

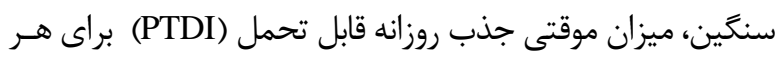
شخص بالغ · و كيلوگرمى از طريق معادلات زير استفاده شـد كـهـ

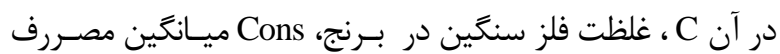

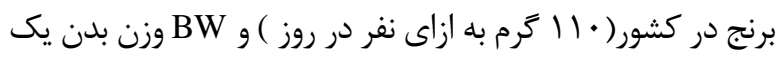

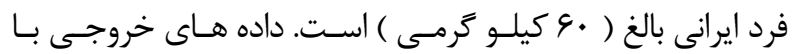
WHO/FAO و سطح استاندارد ايران مقايسه شد.

$\mathrm{PTDI}=\mathrm{C} \times$ Cons $/ \mathrm{Bw}(\mathrm{r})$

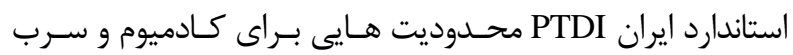

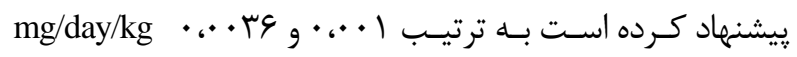

() (1) Bw
و به وزن ثابت رساندن به صورت يـودر در آورده سـيس بــه آن ها هآ

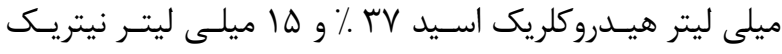

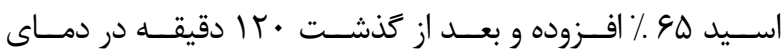

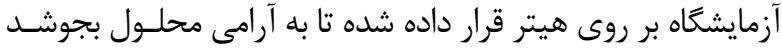
و حجمش به كمتر از • r ميلى ليتربرسد. سـيس محلـول شـفاف بدست آمده، بعد از خنك شدن از كاغذ صافى عبور داده و يسس از

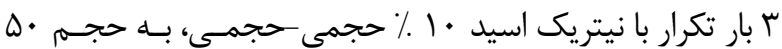
ميلى ليتر رسـانده شـد (9 (، (1). در مرحلـه دوم (شسـته شـدن)،

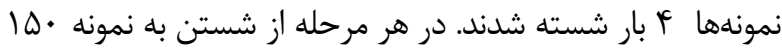

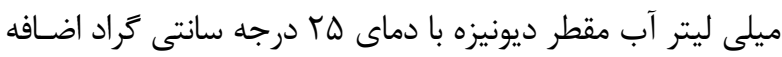
شد و r دقيقه بر روى استيرر قـرار داده شـــ و يسـس از تـه نشـين

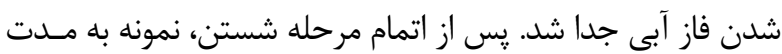

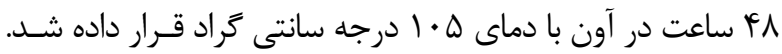

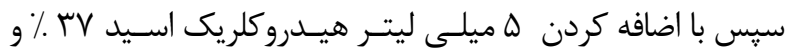

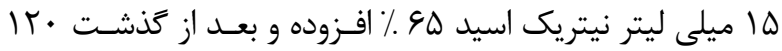

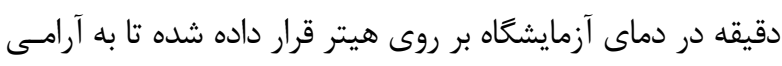

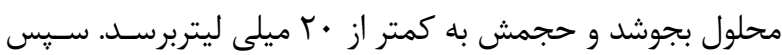

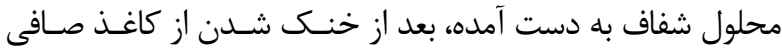

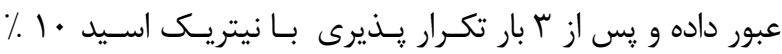

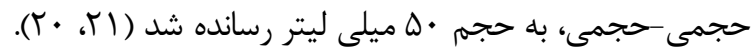

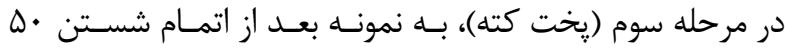

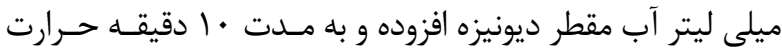

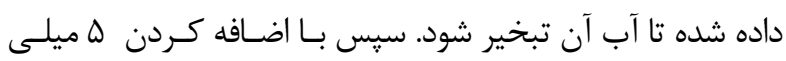

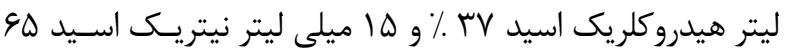

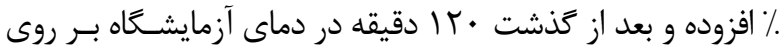
هيتر قرار داده شده تا به آرامى محلول بجوشد و حجمش به كمتر

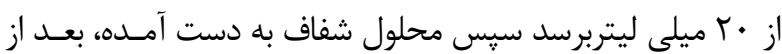
خنك شدن از كاغذ صافى عبور داده و يس از ب بار تكـرار يـذيرى

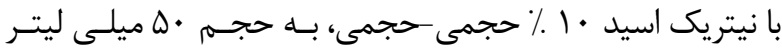

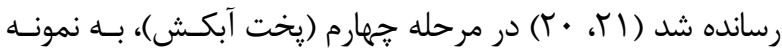
بعد از اتمام شستن • ها ميلى ليتر آب مقطر ديونيزه افـزوده و بــر

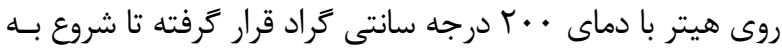
جوشيدن كند. بعد از • ا دقيقه جوشيدن در صافى ريخته شـده و

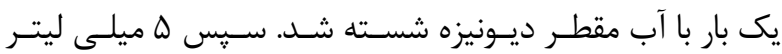

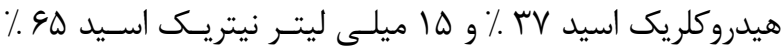

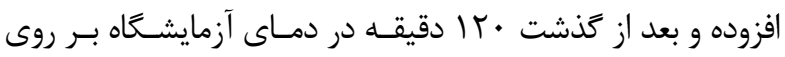
هيتر قرار داده شد تابه آرامى محلول بجوشد و حجمش بـ به كمتر

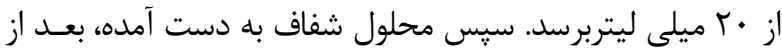
خنك شدن از كاغذ صافى عبور داده و يس از ب بار تكـرار يـذيرى

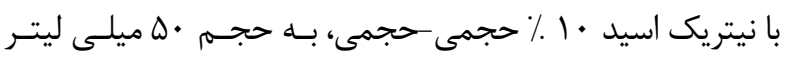




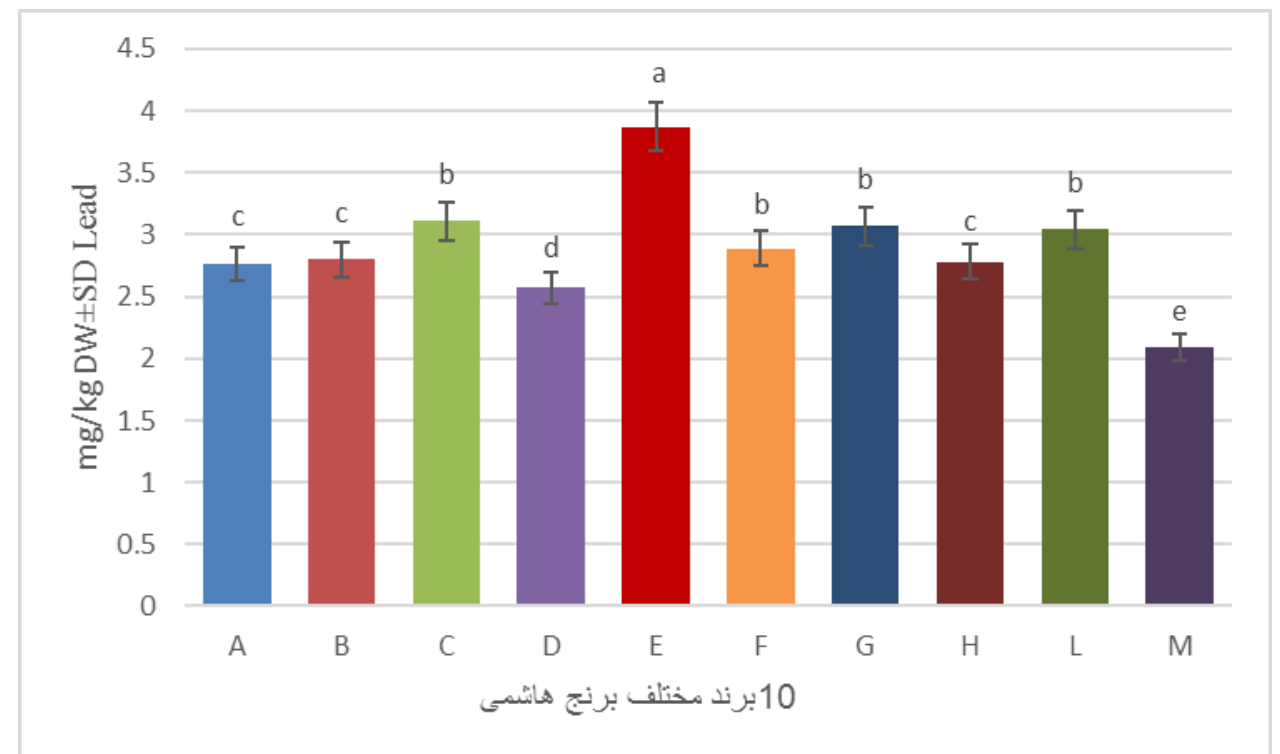

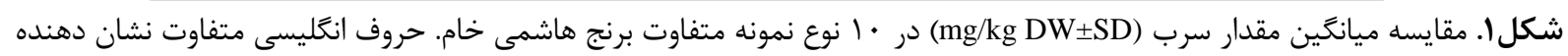

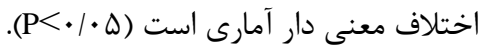

مقايسه ميزان سرب در · المونه متفاوت برنج هاشمى خام در برندهاى مختلف كه به صورت تصادفى خريدارى شده در نمودار 1 مشاهده مى شود. ميزان سرب در برنجهاى خام،

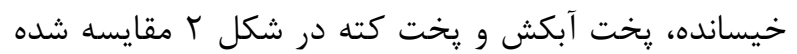
است. آناليز ANOVA نشان داد كه تفاوت معنى دارى بحت بين سرب تمام نمونه هاى برنج هاشمى قبل از تيمار با بيوجاذب

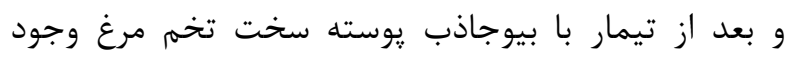
دارد ( ) در نمودار ا ومقايسه اى كه كه بين · ا نمونه ى متفاوت برنج هاشمى خام در برندهاى مختلف كه به صورت تصادفى خريدارى شده اند انجام شد و بر اساس استاندارد

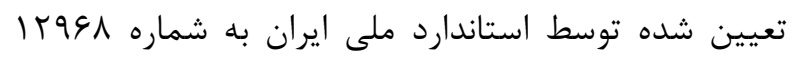

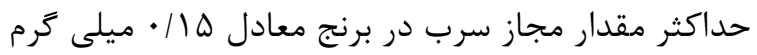

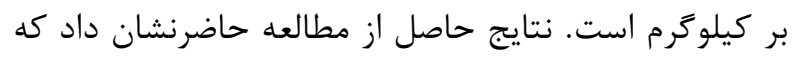
ميزان سرب در تمامى نمونههاى مورد ارزيابى بيشتر از حد

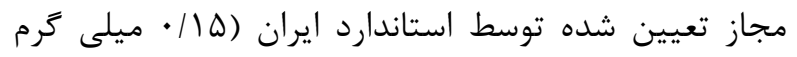

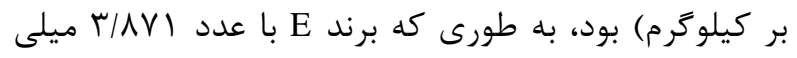

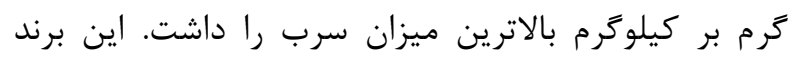

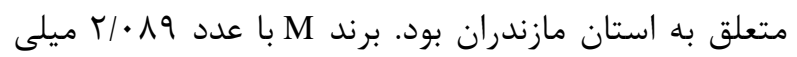

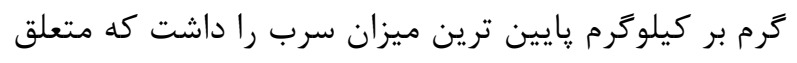

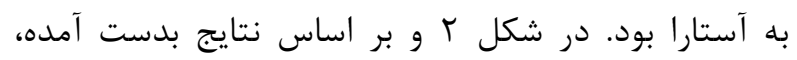
آناليز ANOVA نشان داد كه تفاوت معنى دارى در ميزان سرب در نمونهاى برنج به روشهاى مختلف قبل و بعد از تيمار با يوسته سخت سفيد تخمم مرغ وجود دارد، به طورى به به
تحليل آمارى

ظرفيت يوسته سخت سفيد تخم مرغ در كـاهش فلـزات ســـخين

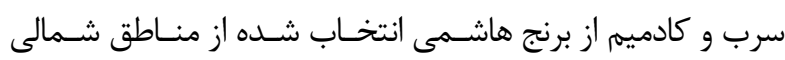
مازندران، كيلان و آستارا در حالات مختلف بررسى شـد. ميـانكًين • ا نمونه با حداقل ץ بار تكرار يذيرى در \& ع حالت برنج خام، بـرنج

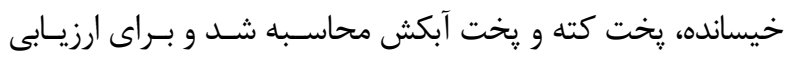

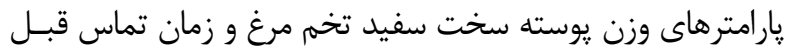

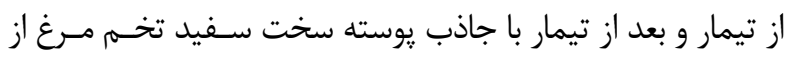

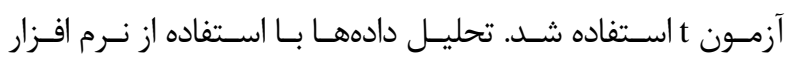

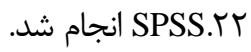

\section{بافته ها}

در ابتدا برنجهاى هاشمى (Oryza sativa) به ب زروها، گروه و زروه بركرفته از استان خيلان، استان مازندران و منطقه آستارا در شمال ايران بودند. استاندارد تحقيقات صنعتى ايران حداكثر

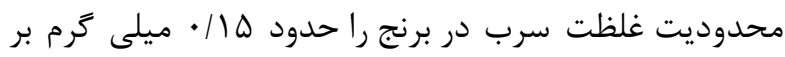

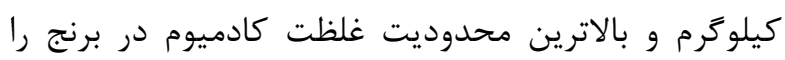

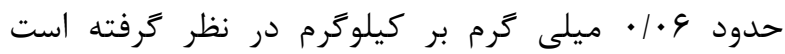

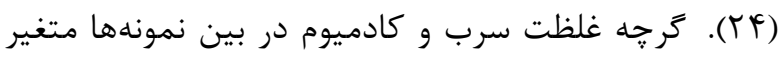

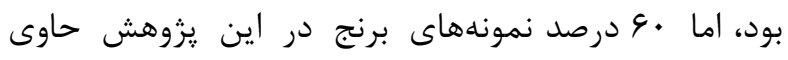

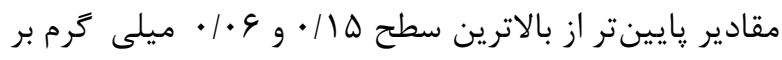
كيلوگرم پيشنههاد شده از سوى استاندارد ايران بودند. 


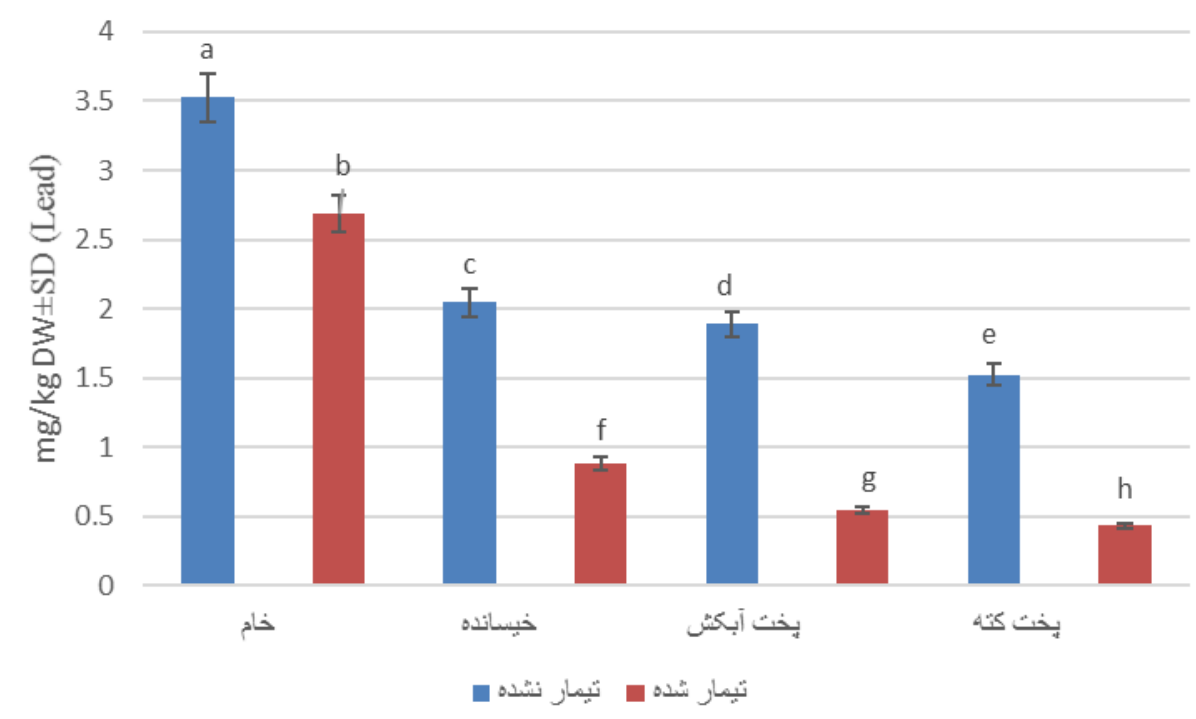

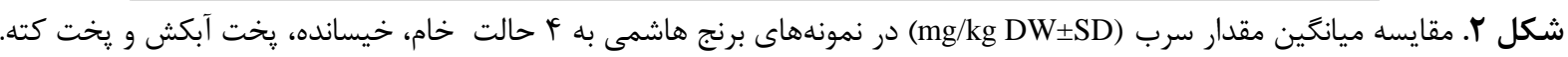

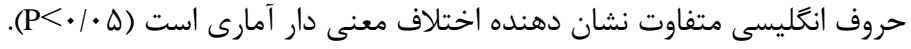

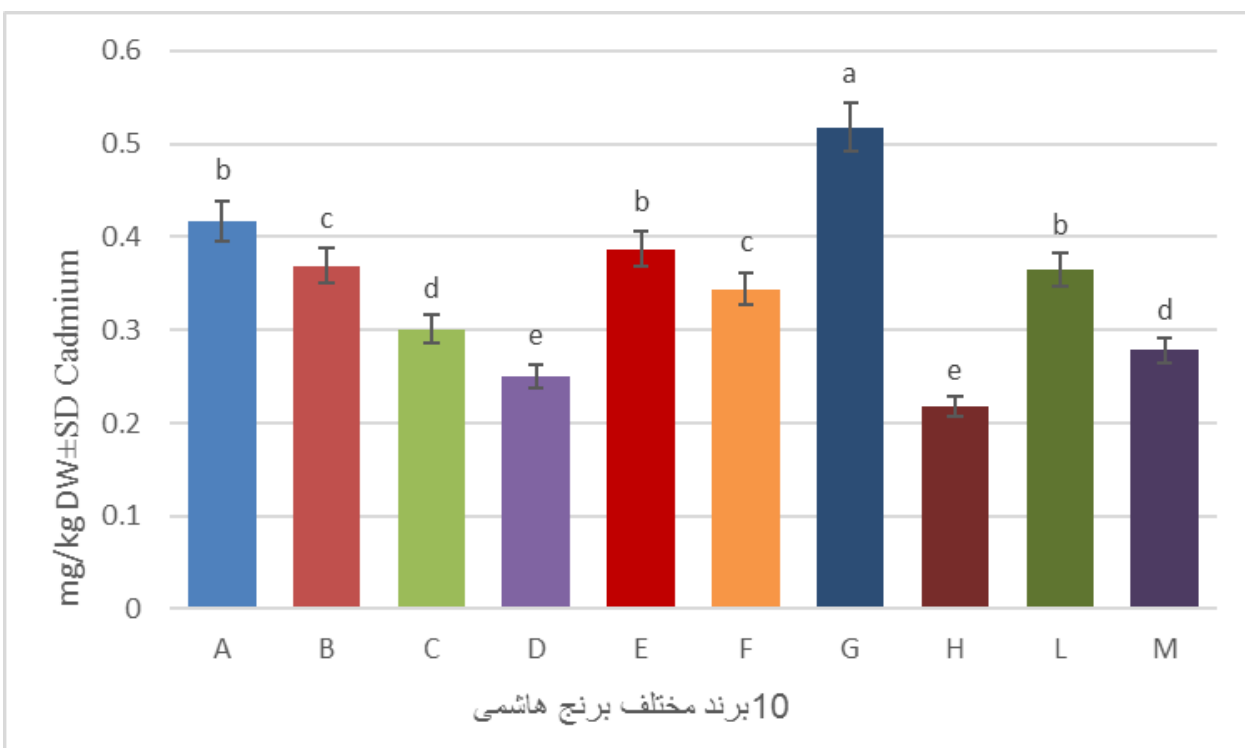

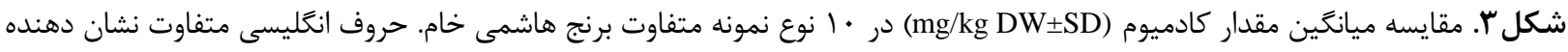

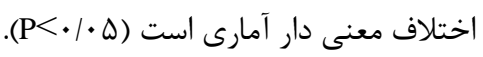

صورت تصادفى خريدارى شده بودند، تفاوت معنى دار بين

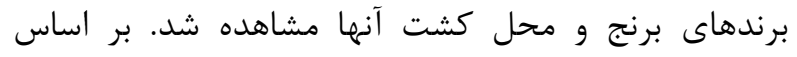

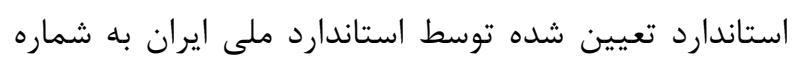

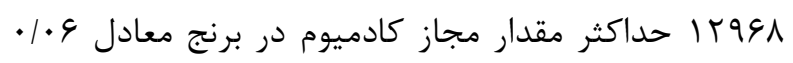

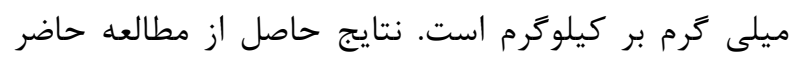

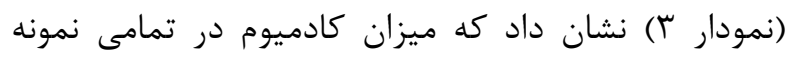

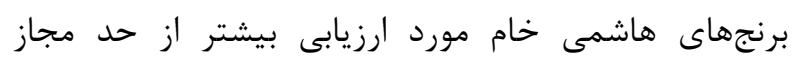

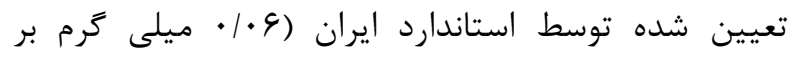

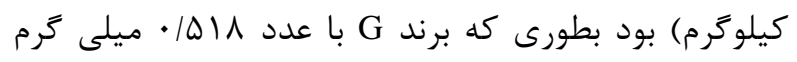

كه بيشترين كاهش ميزان سرب در روش يخت كته تيمار

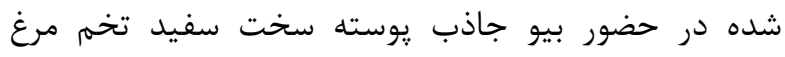

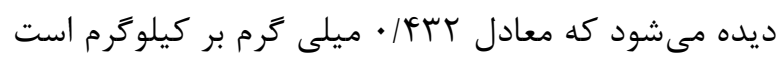

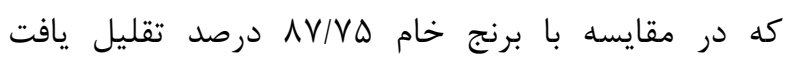
.$(\mathrm{p}<\cdot / \cdot \Delta)$

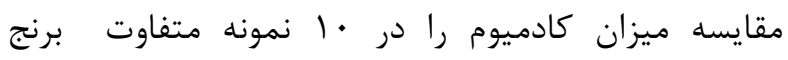

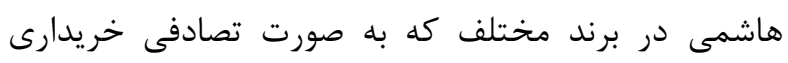

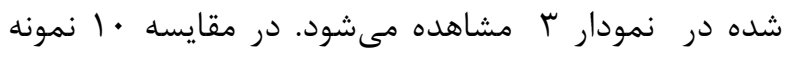

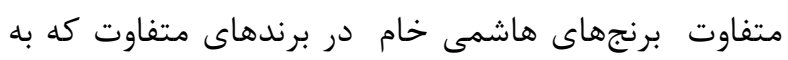




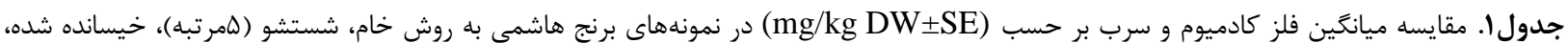

يخت كته و آبكش

\begin{tabular}{|c|c|c|}
\hline 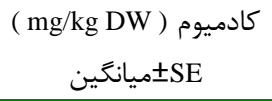 & 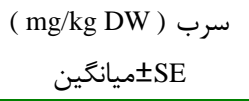 & عنوان \\
\hline $\mathrm{a} \cdot / \mathrm{m} 11 \pm \cdot / \cdot 11$ & ar/DTVE./.91 & برنج خام \\
\hline $\mathrm{b} \cdot / r \Delta \Lambda \pm \cdot / \cdot \Delta r$ & ${ }^{\mathrm{b}} \mathrm{Y} / \varphi \mathrm{I}| \pm \cdot /| \uparrow \mid$ & برنج شسته شده(ه مرتبه) \\
\hline $\mathrm{b} \cdot / T \Delta I \pm \cdot / \cdot \mid \mathrm{F}$ & ${ }^{c} T / \cdot r V \pm \cdot / 1 T G$ & برنج شسته شده با نسبت آب:برنج أl و خيسانده شده با سديم كلريد r٪\% \\
\hline$c \cdot 1 \cdot 9 r \pm \cdot 1 \cdot \cdot 9$ & $\mathrm{e} \cdot|\Lambda \Lambda| \pm \cdot \mid \cdot \Delta \varphi$ & برنج شسته و خيسانده شده با سديم كلريد \% r در حضور يوسته سخت سفيد تخم مرغ \\
\hline 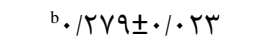 & 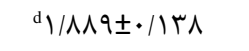 & برنج آبكشى شده بعد از \& مرتبه شستن و خيسانده شده در محلول نمكى \\
\hline$c \cdot / \cdot \wedge \Lambda \pm \cdot / \cdot \cdot \wedge$ & $\cdot \cdot \mid \Delta F \Psi \pm \cdot / \cdot \Delta F$ & برنج آبكشى شده بعد از F مرتبه شستن در حضور يوسته سخت سفيد تخم مرغ و سديم كلريد . \\
\hline $\mathrm{b} \cdot / \mathrm{r} \cdot 1 \pm \cdot / \cdot \cdot \Lambda$ & d) $/ Q Y H \pm .1 .9 \mathrm{~V}$ & برنج كته بعد از ₹ مرتبه شستن \\
\hline $\mathrm{d} \cdot 1 \cdot 49 \pm \cdot 1 \cdot \cdots 9$ & $g \cdot / F T T \pm \cdot r Y$ & برنج كته بعد از F مرتبه شستن در حضور يوسته سخت سفيد تخم مرغ سديم كلريد ب \\
\hline
\end{tabular}

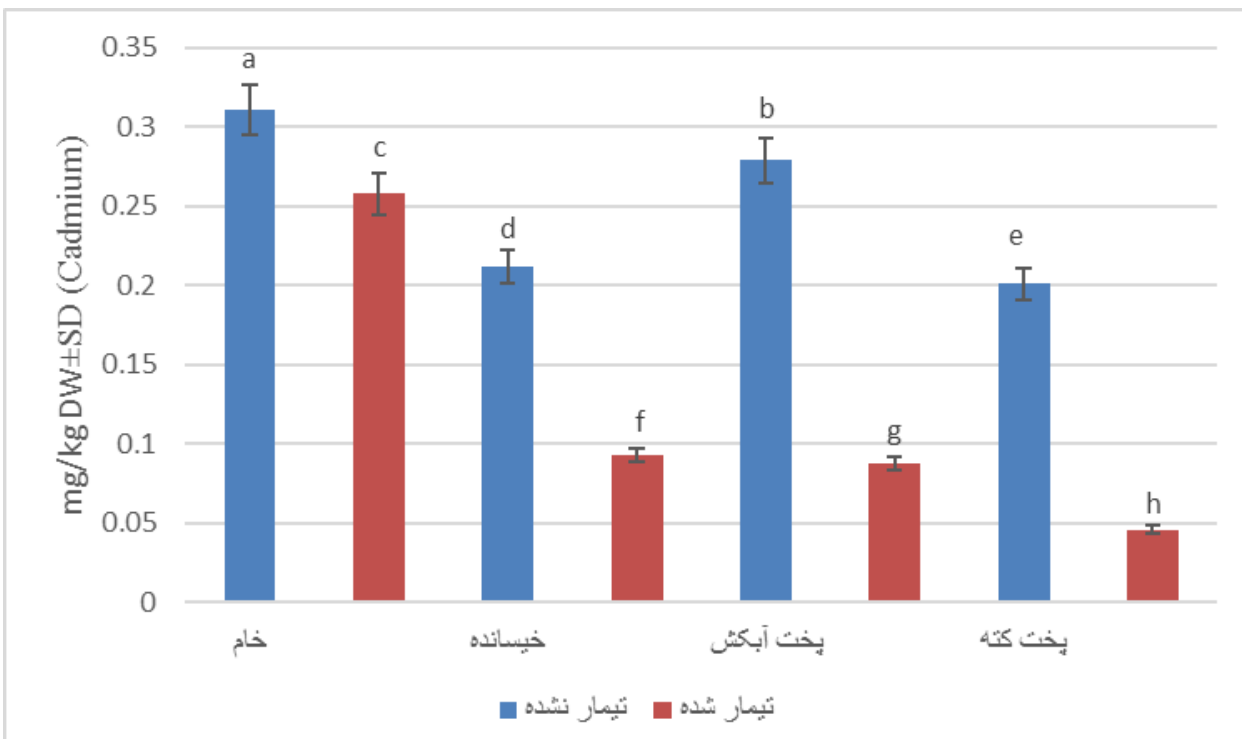

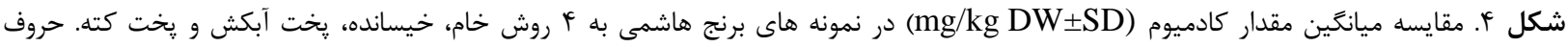

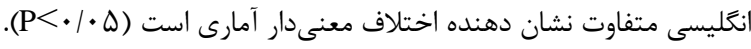

كه ميزان كادميوم در تمامى نمونههاى تيمار شده در حضور بيوجاذب يوسته سخت سفيد تخمم مرغ كمتر از حد

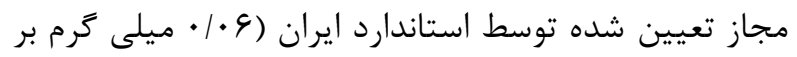
خيلو با توجه به يافته هاى اين تحقيق كه در جدول ا آمده است نتيجهَيرى مىشود كه شستشوى له مرتبه برنجهاى مورد

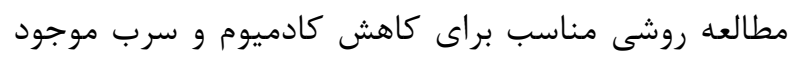
در نمونههاى خام است و خيساندن اين نمونهها در حضور جاذب زيستى يوسته سخت و سفيد تخم مرغ مىتواند

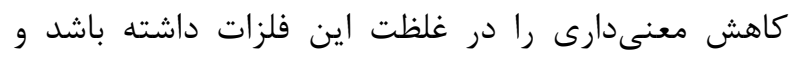
همجنين در روش يخت كته ميزان سرب و وان كادميوم به

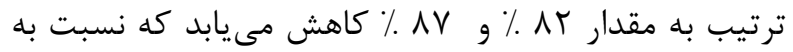

بر كيلوگرم بالاترين ميزان كادميوم را داشت و برند

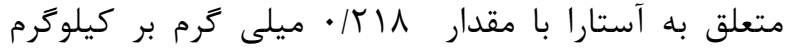
يايينترين ميزان سرب را داشت. ميزان مقايسه كادميوم در

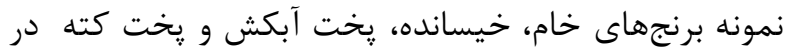
شكل f مشاهده مىشود. آناليز ANOVA نشان داد كه تفاوت معنى دارى بين ميزان كادميوم تمام نمونههاى برنج هاشمى قبل از تيمار با بيوجاذب و بعد از تيمار با بيوجاذب ميرن يوسته سخت تخم مرغ وجود دارد، به طورى كه بيشترين كاهش ميزان كادميوم در روش يخت كته تيمار شده در حضور بيو جاذب يوسته سخت سفيد تخم مرغ ديده شد كه

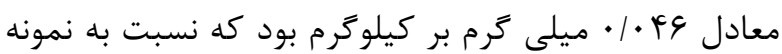

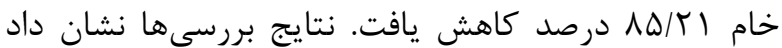


سنغين نسبتاً قابل حل در آب هستند؛ بنابراين در خاك سيال بوده و تمايل به تجمع زيستى دارند. مواد با طول عمر بالا مانند قاب ينجرههاى PVC، يلاستيكها و يلاتين موجود در فولاد منابع اصلى كادميوم در محيط زيست هستند. كادميوم در بدن بان باندان

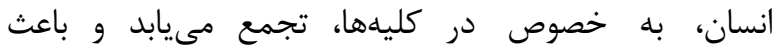

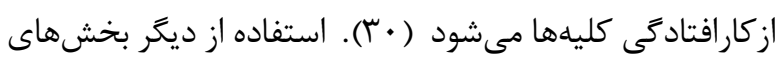

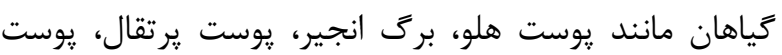

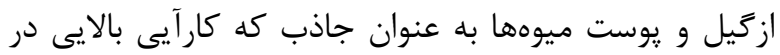

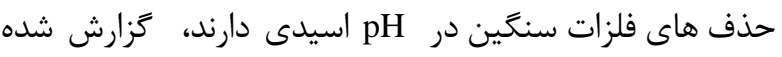

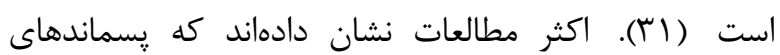
كشاورزى حه به فرم طبيعى خه به فرم اصلاح شده كارآيى

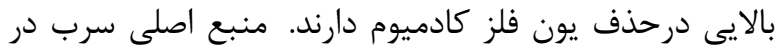

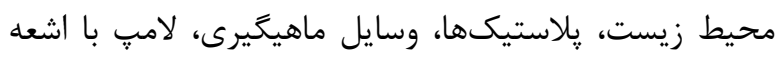
كاتدى، سراميك، لحيه، قطعات سرب تابان و محصولات ديخر مانند فولاد و كابلهاى بازيافتى هستند. سرب ميتى إتواند باعث

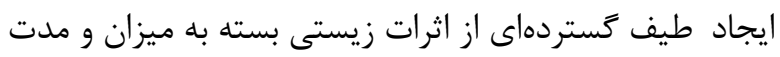

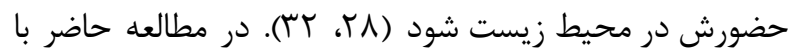

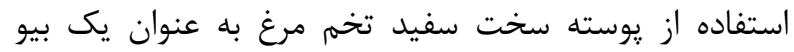

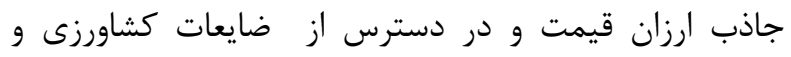

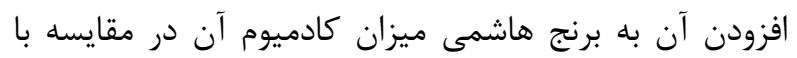

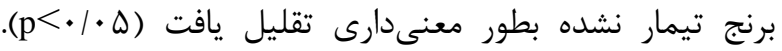

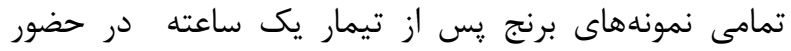

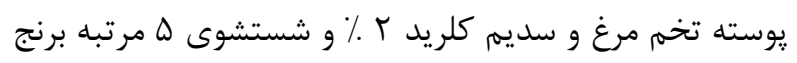
خام در مرحله ابتدايى هملىى به سطح مقادير فلزات سنَّين

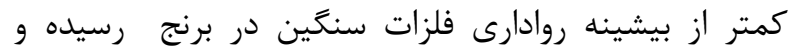

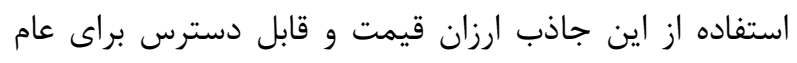

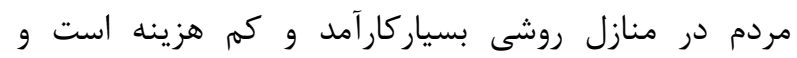

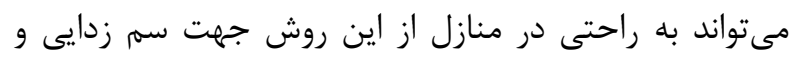

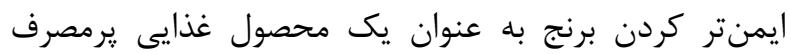
استفاده شود. در مقايسهاى كه بين نمونه برنج خام و برنج ه مرتبه شستشو

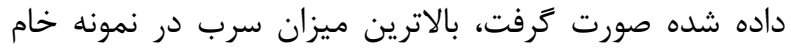

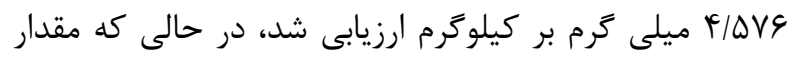

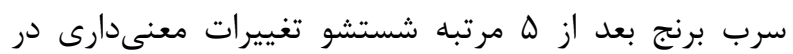

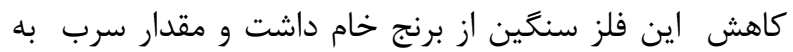

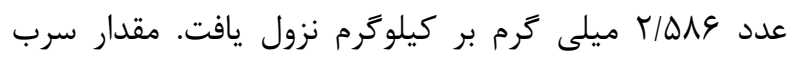

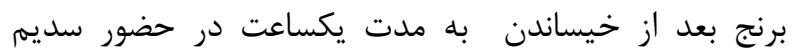

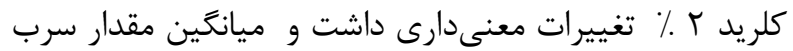

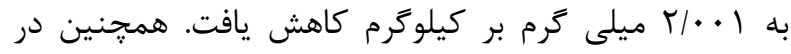

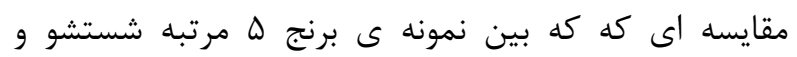

روش تخت آبكش به ترتيب ه ٪ و ٪ ٪ بيشتر و موثرتر

\section{بحث}

فلزات سنگين از جمله آلايندهاى زيست محيطى هستند كه

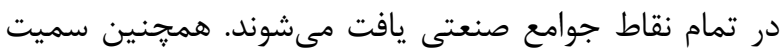

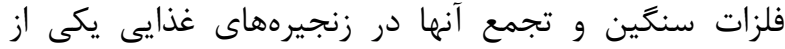

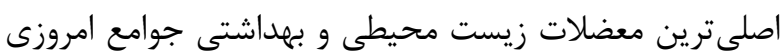

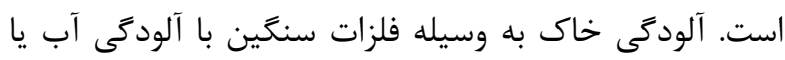

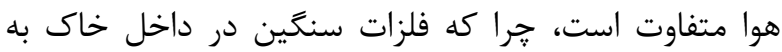
مدت طولانىترى نسبت به ساير بخشهاى بيوسفر باقى

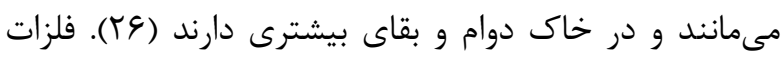

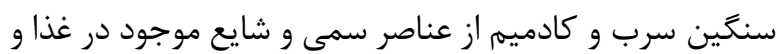
محيط زيست هستند كه عمر و بقاى طولانى در بدن انسان و

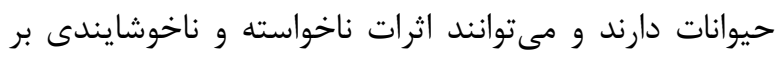

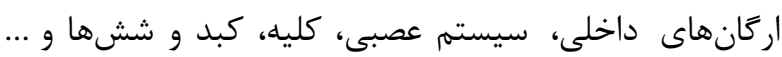
بخذارند. آلودكى مواد غذايى و محصولات كشاورزى به فلزات آنات

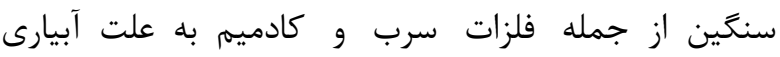
فاضلابهاى شهرى، حشره كشها و كودهاى شيميايى و ... رخ مى دهد و همجنين در تمامى كشت، برداشت، انبار كردن و حمل و نقل و بسته بندى اين امكان وجود دارد. در ضمن رابطه دمان

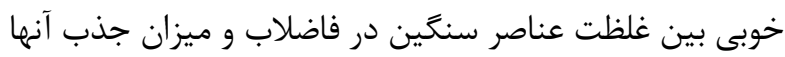

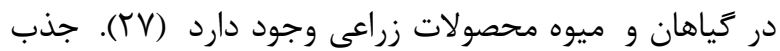

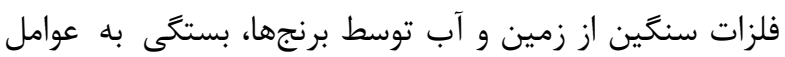

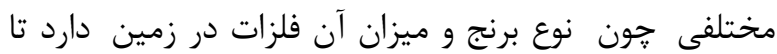

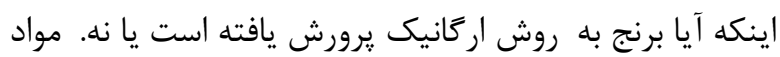
يسماند كشاورزى معمولا شامل ليخنين و سلولز به عنوان اجزاى تشكيل دهنده اصلى هستند. ديكر تركيبات شامل همى سلولز، ليييدها، يروتئين ها، قندهاى ساده، نشاسته، آب، هيدروكربنها خاكستر و تركيبات بسيار ديكر كه حاوى يك لئن

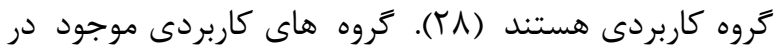

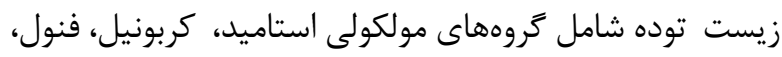

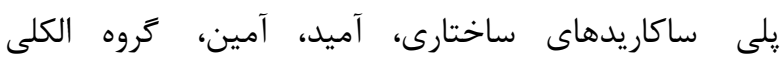
سولفيدريل كربوكسيل و استرها هستند. اين گروهها ارتباط

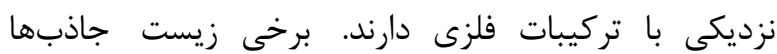

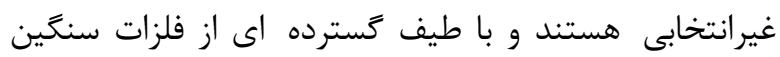
ارتباط دارند، درحالى كه برخى ديخر مخصوص انواع خاصى از فلزات هستند كه بستكى به تركيبات شيميايى آنها دارد ( (T)، 9ץ). فلزات سنَين كادميوم و سرب در مقايسه با ديكر فلزات 
سرب و كادميم را اندازه گرفتند. نتايج نشان داد كه شستن برنج حداقل F أبار، تاثير قابل ملاحظهاى در كاهش سرب و

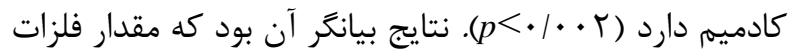
سنگين در برنج قهوهاى كمتر از بيشينه حد مجاز استاندارد

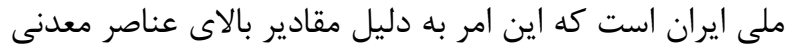
مثل زينك، آهن و منگنز است (سM). محور اصلى مطالعه حاضر بر استفاده از يوسته سخت سفيد تخم مرغ مغ به به عنوان بيوجاذب بود كه فلزات سنگين كادميم و سرب را به ميزان معنى دارى كاهش داد، به طورى كه ميانگين فلزات سنگين

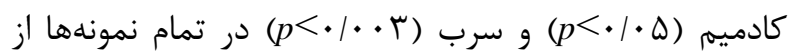
حد مجاز كمتر شد. زيارتى و عليدوست سحرخيز لاهيجى در سال هوسا تحقيقى انجام دادند و خاصيت بيوجاذب شلتوك برنج بر شاليزار برنج هاشمى واقع در رودبنه از توابع شهرستان لاهيجان بررسى شد تا ميزان كاهش فلزات سنگين سرب، نيكل و كادميم بررسى رونى

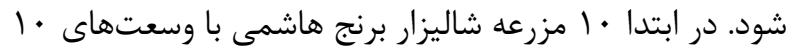

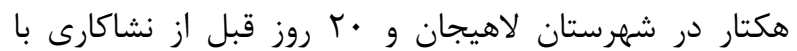
افزايش مقادير مشخص و متفاوت از شلتوك برنج به مساحت

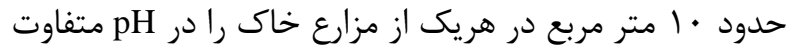

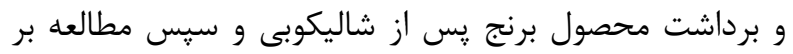
روى برنج عرضه شده از اين مزارع در حالت خام، خيسانده، كته، و آبكش و تعيين مقادير فلزات سنگين سرب، كادميه، و ورئ نيكل به روش هضم مرطوب و توسط دستخاه اسِكتروفتومترى

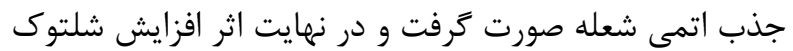
در خاك مزارع و عدم حضور شلتوى بر روى • أن نمونه برنج مقايسه شد. آنها مشاهده كردند كه ميزان كادميم در برنج خام

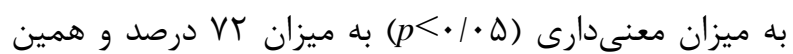
طور ميزان سرب و نيكل نيز به ميزان معنى

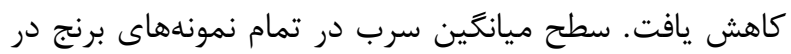

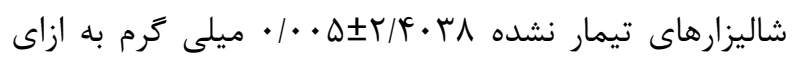
هر كيلوگرم بود كه اين ميزان براى شاليزارهايى كه توسط

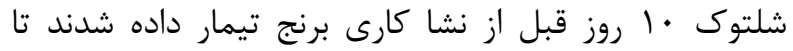

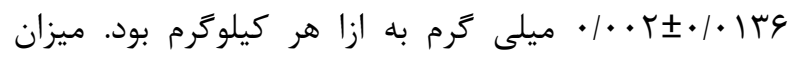

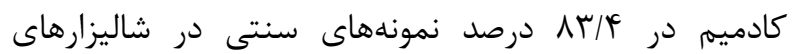
رودبنه بيشتر از حداكثر مجاز سازمان استاندارد ملى ايران

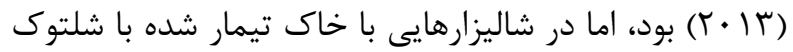
تمام نمونهها كمتر از سطح مجاز شد. نكته برجسته اين مطالعه ظرفيت شلتوك برنج در كاهش غلظت فلزات سنگين سرب، كادميم و نيكل از خاك و برنج هاشمى مورد عرضه به بازار است. وجه تشابه اين تحقيق با مطالعه مورد نظر در
خيسانده شده در حضور سديم كلريد. حاكى از آن است كه ميزان سرب در نمونه برنج ه مرتبه شسته شده، T/AFT ميلى گرم بر كيلوگرم ارزيابى شد كه

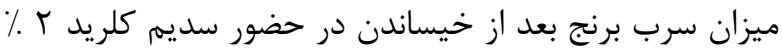

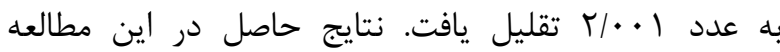
بيانگر آن بود كه نمونههاى برنج كه در له مرتبه شسته نشده

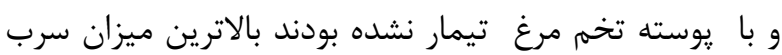

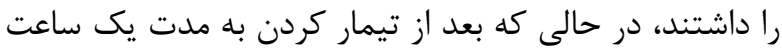
در حالت خيسانده شده و مجاورت بيوجاذب يوسته سخت

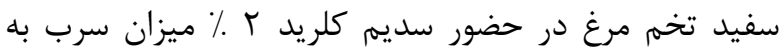

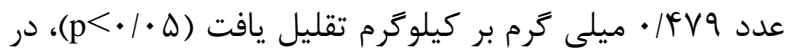

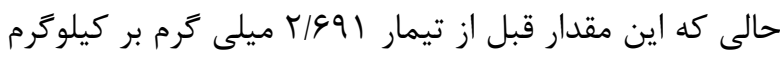

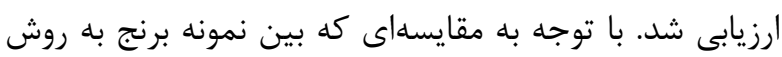
تخت آبكش تيمار نشده و يخت آبكش تيمار نشده در حضور سديم كلريد r \% \%، و يخت آبكش تيمار شده در حضور يوسته سخت سفيد تخم مرغ و سديم كلريد ب ٪ ٪ صورت كرفت،

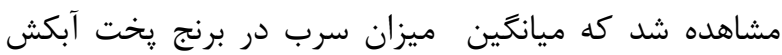

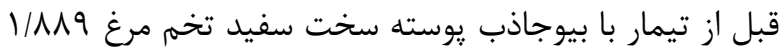

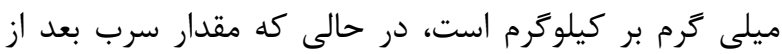
تيمار كردن با بيوجاذب يوسته سخت سفيد تخم مرغ در

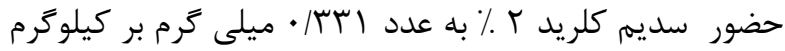

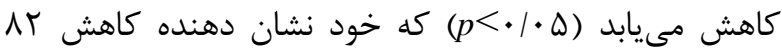
درصدى ميزان سرب است. آناليز ANOVA نشان داد كه تفاوت معنىدارى در ميزان سرب برنج به روشهاى مختلف ميرن قبل و بعد از تيمار با يوسته سخت سفيد تخمم مرغ وجود دارد، مدي، به طورى كه بيشترين كاهش ميزان سرب در روش يخت كته تيمار شده در حضور بيوجاذب يوسته سخت سفيد تخم نيز

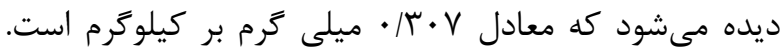

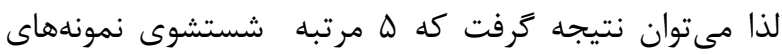

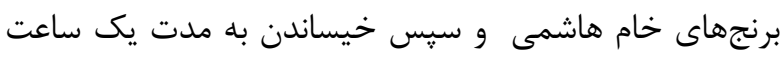
در حضور سديم كلريد ؟٪٪ و جاذب زيستى يوسته سخت سفيد تخم مرغ به عنوان ضايعات مصرفى مواد غذايى مىتواند روش بهينهاى براى حذف فلزات سنگين سرب و كادميوم باشد. به علاوه، روش ڤخت كته عله علاوه بر كاهش بيشتر فلزات به حفظ خواص برنج و ويتامينهاى آن كمك مىكند؛ يس مىتوان بدون وجود خطر از رخت برنج به به عنوان وعده غذايى مفيد استفاده كرد. درمطالعه اي در سال سوسا، زيارتى و عزيزى • •1 نمونه برنج على كاظمى را به صورت تصادفى از استان كيلان انتخاب كردند و تاثير شستشو و روشىهاى مختلف يخت بر ميزان 
تيمار نشده I 9 •|••

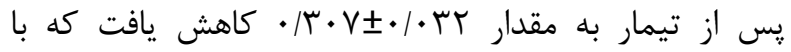
مطالعه حاضر از لحاظ كاهش ميزان فلزات سنخين وجه تشابه

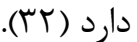
با توجه به دادههاى حاصل از اين مطالعه با مطالعات قبلى

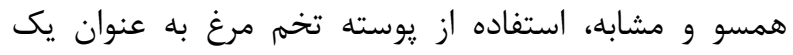
جاذب زيستى ارزان قيمت و دور ريز خانگى توصيه مىشود.

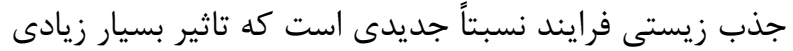

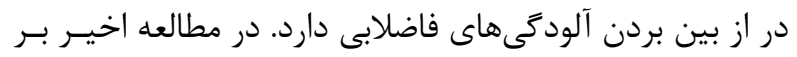

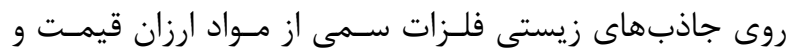

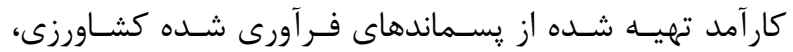
غذايى و سبزى نشان داد كه اين مواد جايگزين مناسبى بـراى

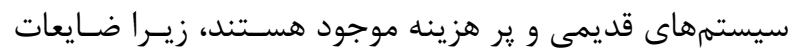
كشاورزى تجديد يذير هستند و ميل تركيبى زيادى بـا فلـزات سنگين نيز دارند (عَ). استفاده از اين جاذبهاى زيستى ارزان

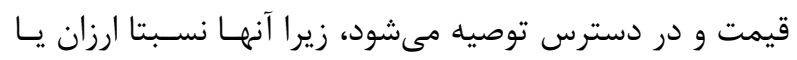
مجانى بوده، به راحتى در دسترس هستند، تجديدٍ كارايى بالايى در جذب فلزات سنگين دارند. نتايج اين مطالعـه ثابت كرد كه بيوجاذب يوسته سخت سفيد تخم مرغ يتانسـيل

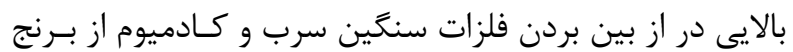
كه غذاى ثابت اكثر مردم ايران و ديخر كشورهاست، دارد.
ظرفيت شلتوك برنج با ظرفيت يوسته سخت سفيد تخم مرغ به عنوان جاذب زيستى است. نتايج نشان داد كه حضور بيوجاذب به عنوان يك بيوجاذب ارزان قيمت تاثير معنى دارى بر كاهش فلزات سنخين از جمله فلزات سنگين سرب و و كادميوم دارد كه با تحقيق مورد نظر مطابقت دارد (Yr). زيارتى و قلى زاده در سال هوسا يزوهشى تحت عنوان كاربرد

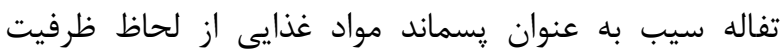
جذب زيستى يونهاى فلزى سمى سرب و كادميوم و نيكل برنج طارم كاشت شده در شهرستان بابل در شمال ايران انجام

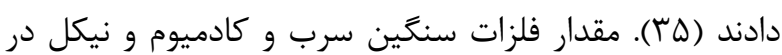
نمونههاى تفاله سيب مورد استفاده كه از كارخانجات صنايع غذايى از جمله سن ايج تهيه شده بود به عنوان بيوجاذب لمان

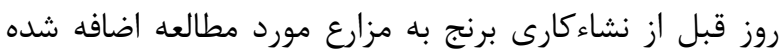

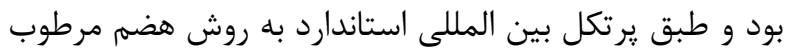

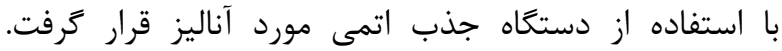

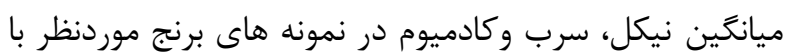
استفاده از ANOVA در حضور و عدم حضور بيوجاذب مورد تجزيه و تحليل واقع شدند. اين مطالعه نشانگر اين واقعيت بود كه غلظت سرب در برنج خام مورد مطالعه كه با بيوجاذب

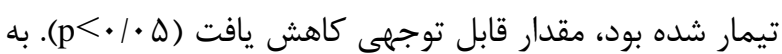
اين صورت كه تمام نمونهاى برنج مورد مطالعه در برنج خام

\section{REFERENCES}

1. Ziarati P, Arbabi S, Arbabbi-Bidgoli S, Qomi M. Determination of lead and cadmium contents in (Oryza Sativa) rice samples of agricultural areas in Gilan, Iran. Int J Food Allied Sci 2013; 2: 268- 271.

2.Bailey, SE, Olin TJ, Bricka RM, Adrian DD. A review of potentially low-cost sorbents for heavy metals: Water Res 1999; 33: 2469-2479.

3.Thomsen MH. Complex media from processing of agricultural crops for microbial fermentation. Appl Microbiol Biotechnol 2005;68: 598- 606 .

4.Hashem A, Akasha RA, Ghith A, Hussein DA. Adsorbent based on agricultural wastes for heavy metal and dye removal: a review. Energy Edu Sci Technol 2005;19:69-86.

5.Ayyappan R, Carmalin Sophiab A, Swaminathan K, Sandhya S. Removal of Pb(II) from aqueous solution using carbon derived from agricultural wastes. Process Biochem 2005;40: 1293-1299.

6.Dhiraj S, Garima M, Kaur MP. Agricultural waste material as potential adsorbent for sequestering heavy metal ions from aqueous solutions, a review. Bioresoure Technol 2008;99: 6017-27.

7.Namasivayam, C, Ranganathan, K. Removal of $\mathrm{Pb}$ (II), $\mathrm{Cd}(\mathrm{II})$ and $\mathrm{Ni}(\mathrm{II})$ and mixture of metal ions by adsorption onto waste $\mathrm{Fe}(\mathrm{III}) / \mathrm{Cr}(\mathrm{III})$ hydroxide and fixed bed studies. Environ Technol 1995; 16: 851-60.

8.Nys Y, Gautron J, Garcia-Ruiz JM, Hincke MT. Avian eggshell mineralization: biochemical and functional characterization of matrix protein. C R Palevol 2004;3:549-562.

9.Ar A, Rahn H, Paganelli CV. The avian egg. Mass and strength. C R Palevol 1979; 81: 331-337.

10.Macneil J. Composition of egg shell. Egg Indust 1997;102:15-17.

11.Hincke MT, Gautron J, Panheleux M, Garcia-Ruiz J, McKee MD, Nys Y. Identification and localization of lysozyme as a component of eggshell membranes and eggshell matrix. Matrix Biol 2000;19: 443-453.

12.Kremer B, Kazmierczak J, Stal LJ. Calcium carbonate precipitation in cyanobacterial mats from sandy tidal flats of the North Sea. Geobiology 2008; 6: 46-56. 
13.Food and Nutrition Board (FNB), Institute of Medicine (IOM). Dietary reference intakes for calcium, phosphorus, magnesium, vitamin d, and fluoride Washington (DC): National Academies Press (US); 1997.

14.Balaban RS, Bader JP. The efficiency of $(\mathrm{Na}++\mathrm{K}+)$-ATPase in tumorigenic cells. Biochim Biophys Acta 1983;730:271-275.

15.Cooke AS, Balch DA. Studies of membrane, mammilary cores and cuticle of the hen egg shell. Br Poul Sci 1970;11: 345-352.

16.Haji Ghasemkhan A. Industrial toxicology. Tehran: Baraye Farda Pub; 2007. [In Persian]

17.AOAC. The association of analytical communities focuses on method validation and laboratory quality assurance: Official methods of analysis. Gaithersburg, USA: AOAC International; 1998.

18.ASTM D4638-16, Standard Guide for Preparation of Biological Samples for Inorganic Chemical Analysis. West Conshohocken, PA: ASTM International; 2016.

19.Jaffari-Moghadam R, Ziarati P, Salehi-Sormaghi MH. Comparative perspective to the chemical composition of imported rice: association of cooking method. Biomed Pharmacol J 2015; 8: 149-55.

20.Ziarati P, Moslehisahd M. Determination of heavy metals $(\mathrm{Cd}, \mathrm{Pb}, \mathrm{Ni})$ in Iranian and imported rice consumed in tehran. Iranian Journal of Nutrition Sciences \& Food Technology 2017; 12: 97-104.

21.Jafari- Moghadam R, Ziarati P. Reduction of arsenic content in imported polished rice: association of cooking method. J Chem Pharm Res 2016; 8:622-7.

22.Husoon ZA, Al-Azzawi MNA, Al-Hiyaly SAK. Investigation biosorption potential of copper and lead from industrial waste water using orange and lemon peels. Iraqi J Med Sci 2013; 16: 713-9.

23.Niu H, Volesky B. Characteristics of anionic metal species bisorption with waste crab shells. Hydrometallurgy 2003; 71: 209-15.

24.Iranian National Standardization Organization; 2013. [Available from: http://www.isiri.com]

25.Codex Alimentarius Commission. Codex Committee on Contaminants in foods. Accessed at: July 2011. [Available from: www.codexalimentarius.org.]

26.Garg UK, Kaur MP, Garg VK, Sud D. Removal of hexavalent Cr from aqueous solutions by agricultural waste biomass. J Hazard Mater 2007;140:60-68.

27.Gupta VK, Ali I. Utilization of bagasse fly ash (a sugar industry waste) for the removal of copper and zinc from wastewater. Sep Purif Technol 2000; 18: 131-14.

27.Bayramoglu GA, Denizli S, Bektaş MY. Arica. Entrapment of Lentinus sajor-cajuinto Ca-alginate gel beads for removal of $\mathrm{Cd}$ (II) ions from aqueous solution: preparation and bio-sorption kinetic analysis. Microchem J 2002; 72: 63-76.

29. Wang J C, Weissman G. Ramesh R. Varadarajan J R. Benemann. Parameters for removal of toxic heavy metals by water milfoil. Bull Environ Contam Toxicol 1996; 57:779- 786.

30.Ahluwalia SS, Goyal D. Removal of heavy metals from waste tea leaves from aqueous solution. Eng Life Sci 2005; 5:158-162.

31.Sud D, Mahajan G, Kaur MP. Agricultural waste material as potential adsorbent for sequestering heavy metal ions from aqueous solutions - a review. Bioresource Technol 2008;99:6017-6027.

32.Gholizadeh E, Ziarati P. Remediation of contaminated rice farmlands soil and oryza sativa rice product by apple pomace as adsorbent. Biosci Biotech Res Asia 2016;13:2245-2253..

33. Ziarati P, Azizi N. Chemical characteristics and mineral contents in whole rice grains, hulls, brown rice, bran and polished Ali Kazemi rice in Gilan province-North of Iran. Intl J Farm 2013; 2: 1203-68.

34. Alidoost Saharkhiz Lahiji F, Ziarati P, Jafarpour A. Potential of rice husk biosorption in reduction of heavy metals from oryza sativa rice. Biosci Biotech Res Asia 2016;13: 2231-2237.

35. Ziarati P, Mostafidi M, Shirkhan F, Tamaskoni Zahedi M. Analysis of removal methods of toxic heavy metals using bio-absorbs. Technogenic and Ecological Safety 2018; 4: 62-76.

36. Razafsha A, Ziarati P. Removal of heavy metals from Oryza sativa rice by sour lemon peel as bio-sorbent. Biomed Pharmacol J 2016;9:21-26. 